\title{
o desenvolvimento do setor artesanal paulista: uma análise crítica da sua qualificação gerencial
}

Miguel Angelo Hemzo ${ }^{1}$, Josmar Andrade ${ }^{1}$, Roberto Mauro dos Santos ${ }^{1}$

\footnotetext{
${ }^{1}$ Escola de Artes, Ciências e Humanidades da Universidade de São Paulo (EACH-USP).

Correspondência: E-mail: mahemzo@usp.br

Escola de Artes, Ciências e Humanidades (EACH-USP)

Av.Arlindo Béttio, 1000 - CEP: 03828-000 - São Paulo - SP - Brasil
}

Resumo Segundo o Ministério do Desenvolvimento da Indústria e Comércio a atividade artesanal representa $2,8 \%$ do PIB nacional, envolvendo 8,5 milhões de pessoas. Além de sua importância econômica, este tipo de atividade também fortalece a identidade nacional e tem grandes impactos culturais. Contudo é pouco estudada pelo ponto de vista gerencial, merecendo maior atenção pela sua importância estratégica. Este artigo tem o intuito de analisar, crítica e negocialmente, a condição do setor. Por meio de estudo exploratório que observou as características e atividades de 61 grupos de artesãos de várias regiões de São Paulo, os resultados indicam a necessidade de maior conhecimento gerencial por parte dos artesãos de forma a aumentar sua autonomia e visão sistêmica do processo, sem depender continuamente de posturas paternalistas e assistencialistas de agências governamentais e organizações de terceiro setor. Isso seria muito importante para alavancar o potencial inclusivo e sustentável desta atividade, especialmente junto a setores mais pobres da sociedade, sendo importante, ao mesmo tempo, estabelecer condições para preservação do valor cultural deste tipo de produção.

Palavras-chave: artesanato, setor artesanal, estratégia, visão sistêmica.

Abstract

According to MDIC, the economic activity of the handicraft sector represents $2.8 \%$ of Brazilian GNP, involving 8.5 million people. This sector also strengthens national identity and has considerable cultural impact. In spite of that, it has seldom been studied from the managerial viewpoint, deserving more attention due to its strategic 
importance. This article aims to analyze, critically and managerially, the conditions of this sector. Using an exploratory study that observed characteristics and activities of 61 handicraft groups over several regions of the Sao Paulo state, results point to the need of more managerial knowledge from these handcraft people, in order increase their autonomy and systemic view of the process, and to reduce their dependence from paternalist and an assistencialist government agencies and NGOs. This could be of great importance to leverage the potential of inclusiveness and sustainability of this activity, in particular in the poorer sectors of society, and to establish conditions for the preservation of the cultural value of this sector.

Keywords: traditional handicraft, art crafts industry, strategy, systemic perspective.

Resumen Según el Ministerio del Desenvolvimiento de la Industria y el Comercio, la actividad artesanal representa $2,8 \%$ del producto nacional, envolviendo 8,5 millones de personas. Demás de su importancia económica, esto tipo de actividad también fortalece la identidad nacional y tiene grande impacto cultural. Pero es poco estudiada por la visión gerencial y necesita una mayor atención por su importancia estratégica. El artículo tiene el objetivo de analizar, crítica e negociablemente, la condición del sector. Fue realizado un estudio exploratorio que observó las características y actividades de 61 grupos de artesanos de varias regiones de São Paulo. Los resultados indican la necesidad de mayor conocimiento gerencial de los artesanos para aumentar su autonomía y visión sistémica del proceso, sin depender continuamente de posturas paternalistas y asistencialistas de las agencias gubernamentales y organizaciones del tercero sector. Eso seria mucho importante para mejorar el potencial inclusivo y sostenible de la actividad, especialmente junto a los sectores más pobres de la sociedad, y, al mismo tiempo, estipular condiciones por la preservación del valor cultural de eso tipo de producción.

Palabras-clave: artesanía, sector artesanal, estrategia, visión sistémica. 


\section{Introdução}

Segundo o Ministério do Desenvolvimento, Indústria e Comércio Exterior (MDIC 2006), o setor do artesanato emprega diretamente 8,5 milhões de trabalhadores no país, que ganham em média de 2 a 3 salários-mínimos, gerando uma receita anual estimada em $\mathbf{R} \$ 28$ bilhões por ano. Isso corresponde a 2,8\% do Produto Interno Bruto (PIB). Mais do que uma grande oportunidade de gerar ocupação e emprego, a cadeia de valor do artesanato, que inclui a obtenção e disponibilização de matéria-prima, a própria confecção de peças e sua distribuição, pode representar importante força motriz para o desenvolvimento local, de forma inclusiva e sustentável (Santos 2010).

O artesanato surge com a necessidade do homem de suprir necessidades físicas e espirituais, indo desde a simples cerâmica para cozinhar alimentos até sofisticados adornos rituais (Pereira 1991). E embora essas necessidades sejam comuns a quase todos os povos, suas soluções e formas variam muito, conforme a influência da configuração geo-ambiental sobre as comunidades residentes e a especificidade de suas culturas (Damante 1980, Megale 2003 Silva e Vidal 1995, Vergara e Silva 2007). Ao voltar-se ao contexto do artesanato paulista, é possível observar uma grande variedade, graças aos diferentes climas, topologias, flora e fauna encontrados no estado e aos variados grupos étnicos que constituíram sua população (indígenas, negros e imigrantes) (Santos, 1983).

No estado de São Paulo a Superintendência do Trabalho Artesanal nas Comunidades (SUTACO 2011) tem por responsabilidade oferecer oportunidades de geração de trabalho e renda aos artesãos, por meio de cadastramento, emissão de nota fiscal, qualificação e requalificação, acesso a microcrédito, orientação técnica e jurídica, além de ser a coordenadora do Programa de Artesanato Brasileiro (PAB) do MDIC no âmbito estadual. Vinculada à Secretaria do Emprego e Relações do Trabalho, a Superintendência se relaciona com 62.000 artesãos cadastrados, porém sabe-se que esse cadastro contempla apenas uma parcela desse universo, devido tanto à falta de divulgação, quanto à falta de capilaridade desta autarquia, que depende de convênios voluntários com as Prefeituras. Ainda assim, considerando-se estimativas de que para cada artesão haja três outras pessoas ligadas a esta cadeia produtiva tem-se um universo de quase 200.000 pessoas diretamente ligadas a este tipo de atividade somente no estado.

Apesar de todo o potencial, persiste a carência de estudos que permitam compreender melhor este setor, já que grande parte da pesquisa em Administração não contempla reflexões e práticas de gestão de atividades muitas vezes não formais, voltadas predominantemente à subsistência, nem sempre alinhadas com conceitos e práticas de produção padronizadas e orientadas por escalas pequenas de produção.

Este trabalho assume que o aporte de pesquisas acadêmicas com foco gerencial é fundamental para a consolidação do conhecimento e desenvolvimento da 
Economia Criativa, isto é, aquela que utiliza ativos criativos com potencial de gerar direitos de propriedade intelectual (Reis 2008, ONU 2011). Por esta abordagem, é importante refletir sobre novos paradigmas de gestão de bens, como os lastreados na cultura, que contribuam para torná-los lucrativos, inclusivos e valorizadores da cultura nacional.

O presente estudo busca oferecer um aporte exploratório para melhor definição do contexto da atividade artesanal propondo, a partir da observação crítica das atividades de qualificação de 62 grupos e artesãos que desenvolvem atividades no estado de São Paulo, uma reflexão sobre as necessidades e impactos da qualificação gerencial no setor. Trata-se de um estudo aplicado, baseado na vivência profissional de um dos autores, que foi responsável pela implementação de políticas de qualificação e desenvolvimento empresarial dos grupos de artesanato.

O trabalho está estruturado da seguinte maneira: a partir desta introdução que apresenta o tema, na seção seguinte serão expostas as possíveis razões históricoculturais que contribuem para a falta de interesse, tanto acadêmicas quanto negociais, por este setor culminando em seu estigma e na falta de informações sobre ele e no uso indiscriminado do termo artesanato. Também serão estabelecidas as diferenças entre Arte Popular, Trabalhos Manuais e Artesanato, analisando-os sob as óticas negocial, social e concorrencial. Por fim, apresenta-se - contexto da observação de campo realizada para proceder à análise do ambiente de produção artesanal e as dificuldades encontradas para qualificar gerencialmente artesãos no âmbito do estado de São Paulo, finalizando com a discussão e o direcionamento para novas pesquisas, seguida das limitações desta pesquisa e suas referências bibliográficas.

\section{Revisão da literatura}

A produção artesanal com lastro cultural é uma importante forma de transmissão e preservação do saber-fazer tradicional e, portanto, da identidade e da memória nacionais (ONU 2010), não se encerrando aí sua importância, por também ser valorizada no mercado por se tratarem de peças diferenciadas que carregam em si histórias e traços autênticos (Lewis e Bridges 2004, Gilmore 2008).

Inicialmente as pessoas produziam objetos para suprir suas próprias necessidades, porém, com a evolução da vida em sociedade, os mais hábeis se especializaram e deram origem aos artesãos, que por vezes chegaram a conquistar posições de destaque e poder na sociedade, como ocorreu durante a Idade Média com as Corporações de Ofício (D'Ávila 1984).

A partir da Revolução Industrial, a atividade artesanal passa a uma posição marginal (Cipiniuk 2006) e que perduraria por longo período (Santos 2010). Tal fato pode ser observado de maneira flagrante na utilização do adjetivo "artesanal" 
como mostra o exemplo utilizado pelo dicionário francês Petit Robert: "Artesanal: Que se refere ao artesão. Setor artesanal. Por exemplo: essa atividade ficou artesanal, é artesanal demais: pouco organizada, industrializada." (Robert 1991).

Assim a palavra "artesanato" passou a ser utilizada comumente como o oposto de "indústria" (Lima 2003), sendo vista como uma atividade pouco organizada, genericamente, associada a atributos pejorativos, como ultrapassado, irregular, inconstante e desigual em comparação à eficiência e à padronização dos processos industriais que resultam em produtos seriados e idênticos e que se impuseram desde então (Cipiniuk 2006).

Junte-se a isto a frequente presença do artesanato junto às camadas mais pobres da população e mesmo ao considerar que muitos de seus expoentes delas fazem ou fizeram parte, criou-se então o estigma do artesanato ser atividade de segmentos menos qualificados da sociedade, geralmente de pessoas iletradas e que não se enquadram no moderno sistema de produção empresarial (Ribeiro 1995, Prado Júnior 2001, Lima 2003). Uma exceção onde as atividades artesanais são sinônimo de qualidade e valor é no de Luxo, quando a sua oferta é controlada, tornando-o escasso, e seu valor possui alto conteúdo simbólico (Autor e Silva 2009).

Esse duplo legado depreciativo afetou duramente a trajetória do artesanato brasileiro, que relegado ao segundo plano por uma visão estigmatizada que Ihe atribuía rusticidade, feíura e pobreza, enquanto se assistia, ao longo dos anos, o crescimento e a valorização de produtos industrializados (Santos 1983), estes sim, considerados refinados, belos e elitizados. Produtos e objetos artesanais só voltariam a ser valorizados a partir da segunda metade do século $\mathrm{XX}$, quando os objetos rústicos foram absorvidos pelo comércio como produtos de decoração (Souza 1998), passando a ser valorizados pelo seu aspecto estético/simbólico e não mais por sua função propriamente dita (Cipiniuk 2006). É importante pontuar que ao longo dos anos, pela baixa valorização da atividade artesanal, tendo ela se tornado predominantemente individual ou familiar resultando em pouca expressividade em termos econômicos, vários ofícios artesanais foram extintos, à medida que não foram transmitidos para aprendizes e novas gerações e, assim, morrendo junto com seus mestres.

Como decorrência de todos esses fatores, as manifestações artesanais raramente foram objeto de estudos aprofundados, tendo sido, na maioria dos casos, pesquisadas superficialmente dos pontos de vista cultural e antropológico, apenas como apêndices naturais de outras manifestações ritualísticas, folclóricas ou étnicas, essas sim consideradas mais significativas e relevantes em termos de saber e da cultura populares (Pereira 1991).

Por fim, a exemplo de outras atividades criativas, a atividade artesanal ainda parece sofrer da dicotomia entre valor autoral e valor comercial (Quintana 2003), que faz com que seus autores dediquem a maior parte de seu tempo à criação e 
produção, relegando a gestão do negócio e a comercialização a um segundo plano.

\section{Diferenças entre arte popular, trabalhos manuais e artesanato}

Comumente utiliza-se um único termo: artesanato para nominar o saber fazer do povo manifestado em objetos. No entanto essa designação abarca indistintamente objetos diferentes, que são a arte popular, o artesanato e os trabalhos manuais.

Segundo a portaria no 29 do MDIC (2010), arte popular é a manifestação pessoal de artistas populares que exprimem em peças únicas (não seriadas), espontânea e artisticamente, a sua realidade e sua imaginação. São exemplos a modelagem figurativa em barro e a tradição santeira, dentre outros.

Por se tratar de um tipo de arte, estas peças: (1) são únicas de grande valor cultural e detentoras de altíssimo grau de diferenciação em relação aos concorrentes (obras-de-arte); (2) o mercado consumidor é reduzido, pois seus preços costumam ser superiores aos dos demais produtos artesanais restringindo assim sua demanda; (3) a decisão de compra do consumidor é dependente de formadores de opinião pouco influenciáveis (críticos de arte e marchands principalmente); e (4) a exemplo de outras artes, esse tipo de trabalho depende de dom pessoal, o que torna difícil o ensino da técnica para grupos de trabalho, sendo portanto, atividade essencialmente individual, o que gera pouca absorção de mão de obra, beneficiando poucos indivíduos. Em contrapartida trata-se de componente importante da memória e identidade nacionais (ONU 2010).

Já, os trabalhos manuais, conforme Portaria de 14/03/1995 e Comunicado datado de 02/06/1995 da SUTACO, podem ser definidos como os artefatos que tenham no mínimo $60 \%$ de trabalho manual aplicado à peça. A definição deste porcentual tem por objetivo protegê-los da concorrência predatória de atravessadores e montadores que se passam por artesãos. Trabalhos manuais são reproduzidos a partir de fórmulas e receitas de domínio público com materiais geralmente industrializados, sem traços culturais peculiares. São exemplos desta classe de objetos peças em tricô, crochê e bordado; pintura em panos de prato, ponto cruz, etc. (MDIC 2010).

Por serem de fácil aprendizado e muito úteis, essas técnicas, no período colonial, eram desenvolvidas pelas mulheres para suprir as necessidades de seus lares (Damante 1980, Holanda 1994 Ribeiro 1995), porém com o passar do tempo essas peças passaram a ser vendidas para complementar a renda familiar (Pereira 1991), o que continua a acontecer até hoje. Atualmente há um universo de programas, publicações e cursos que estimulam a produção econômica dos trabalhos manuais, como forma complementar de renda, praticamente banalizando sua execução e fragilizando-os frente à concorrência (produtos 
industrializados, de $\mathrm{R} \$ 1,99$ e outros), pois sua competitividade fica atrelada apenas ao preço.

Desta forma, o mercado consumidor é aparentemente amplo, pois seus preços são baixos, logo, acessíveis à maior parte da população; no entanto como são encontrados em toda parte, seu mercado fica normalmente restrito à própria localidade, e por vezes, se reduz apenas à própria família, amigos e vizinhos. A decisão de compra do consumidor é fortemente orientada para barganha de preços e influenciada por modismos passageiros de origem difusa (produção de velas, sachês, temas como morangos, flores, novelas, etc.) difíceis de controlar.

Apesar da grande capacidade de absorção de mão de obra, por facilitar a formação de grupos de trabalho, devido à saturação desses produtos no mercado os resultados obtidos costumam ser passageiros, pouco rentáveis e de baixo valor cultural (MDIC 2010).

Por fim, é preciso concentrar-se na terceira área de atividade, o artesanato por si próprio. Em São Paulo, o artesanato tem definição clara, conforme Portaria da SUTACO 14/03/1995 e Comunicado datado de 02/06/1995: trata-se de todo e qualquer trabalho manual no qual há mais de $80 \%$ de trabalho das mãos do artesão aplicado à peça. Isso pode ocorrer com ou sem auxílio de instrumentos rudimentares, na transformação de matéria-prima bruta, normalmente comum na sua região de origem, em produto acabado e que traz reflexos claros da cultura local, como, por exemplo, trançados em fibras, cerâmicas, entalhes, tecelagem, etc. Um exemplo de fácil compreensão são as tradicionais garrafas de areia de Morro Branco (Ceará), pois desconsiderando-se a garrafa que foi comprada pronta, mais de $80 \%$ de trabalho manual foi aplicado à peça. O artesão usa matéria-prima comum em sua cidade, a areia, que foi transformada em um produto acabado, que por sua vez retrata cenas que fazem parte de seu entorno (mar, praias, etc.) e de seu cotidiano (vilarejos de pescadores, barcos de pesca, etc.).

Em mercados de intensa competição, é justamente essa identidade cultural que funcionará praticamente como uma marca (Santos 2007) que distingue o artesanato dos demais trabalhos manuais, como também da concorrência dos similares industrializados, importados.

De forma contraditória, graças à globalização que tudo massifica' os objetos artesanais passam a ser valorizados justamente pela simbologia e histórias que Ihes são inerentes, uma vez que representam fonte de expressão autêntica de um povo e suas raízes (Bauman 1999, Megale 2003, ONU 2010).

O artesanato é uma área que emprega mão-de-obra intensiva e que, se encarada de forma gerencial, permite que a técnica seja repassada a grupos que podem formar núcleos produtivos. Políticas de qualificação de artesãos aumentam as possibilidades de inserção competitiva no mercado, pois dessa forma é mais fácil garantir quantidade razoável, qualidade constante e respeito a prazos de 
entrega, não somente para o mercado varejista, como também para o atacadista, reforçando a necessidade e as vantagens da adoção de práticas cooperativas de produção (Vergara e Silva 2007).

Vale ressaltar que o mercado atacadista é uma excelente alternativa para artesãos que trabalham em grupo, pois as compras no atacado ajudam a contornar a forte sazonalidade à qual está sujeita a atividade artesanal. Em outras palavras, o auge de vendas de artesanato no varejo acontece nas altas temporadas do turismo (férias escolares), enquanto que no restante do tempo as vendas geralmente ficam reduzidas; os pedidos atacadistas acontecem justamente em períodos de ociosidade da produção, favorecendo a obtenção de renda melhor distribuída ao longo do ano.

Dessa forma, pode-se especular que dos três tipos de produtos analisados o que apresenta melhores condições negociais e inclusivas é o artesanato, por ser mais competitivo e capaz de absorver razoável contingente de pessoas, ademais passível de se sustentar ao longo do tempo (o mesmo podendo se aplicar aos trabalhos manuais quando portadores de tipicidades locais que os diferenciem (Vergara e Silva 2007)).

\section{Abrangência e delimitação do estudo}

O estudo baseou-se na observação e análise dos resultados do Programa SEBRAE de Artesanato em São Paulo, cujo objetivo era profissionalizar grupos de artesãos que desenvolvessem uma mesma técnica artesanal, estimulando-os a adotar formas cooperativas de produção para conquistar o mercado atacadista. De forma global, o programa buscou oferecer treinamento e consultoria para qualificação comportamental (estímulo ao comportamento cooperativo e ao empreendedorismo); técnica (oficinas de repasse ou nivelamento técnico e de revitalização da técnica por meio de design culturalmente responsável); e gerencial (cursos de marketing, formação de preço e fluxo de caixa, qualidade total, todos especificamente desenvolvidos para público de baixa escolaridade); além de formas de divulgação de produtos, por meio da produção de catálogos estaduais, participação em feiras e rodadas de negócio com varejistas e participação em eventos locais e regionais (SEBRAE-SP 2001).

O universo estudado abrangeu $15 \%$ dos 645 municípios paulistas, ou seja, 167 deles que passaram por visita técnica realizada por um dos autores. No período entre 2000 e 2005, o Programa formou 61 grupos de 15 a 30 artesãos produzindo um mesmo tipo de artesanato, na maior parte das regiões administrativas de São Paulo (SEBRAE-SP 2005). Desta maneira, o estudo usou metodologia exploratória, observacional, a partir de uma amostragem não probabilística intencional, ou seja, quando o pesquisador se dirige intencionalmente ao grupo que pretende sondar, não sendo possível generalizar os resultados da amostra para a população (Martins e Theóphilo 2009). 
Para a investigação recorreu-se à pesquisa documental (Martins e Theóphilo 2009), assim foram analisados os relatórios anuais da Coordenação Estadual deste Programa (SEBRAE SP 2001 a 2005) que compilavam e consolidavam a coleta in loco de observações sobre a evolução cooperativa, empreendedora, técnica, gerencial e comercial dos grupos observados, além de dados sobre os eventos de promoção e comercialização dos quais os grupos participaram.

Também foram utilizados dados primários (de campo) colhidos por um dos autores a partir de observação participante, (quando o pesquisador faz parte do contexto observado (Martins e Theóphilo 2009)).

\section{Discussão e análise dos resultados}

\section{Produção artesanal: uma visão gerencial crítica}

Grande parte das entidades que atuam no atendimento e na qualificação de artesãos foca-se, primordialmente, no estímulo à produção. Esta abordagem mostra-se restritiva, à medida que não contempla a dimensão sistêmica da cadeia de valor que, ao final, estabelece uma produção que, em um cenário ideal, não paternalista, deve ser escoada de forma economicamente vantajosa para os produtores. Quando se considera o ambiente interno das inter-relações entre agentes da atividade artesanal, é preciso estimular o trabalho cooperativo, no sentido de capacitar os artesãos técnica e gerencialmente, melhorar os processos de produção, divulgar os produtos, estudar as possibilidades de comercialização de forma a atender aos desejos e expectativas dos clientes e aos requisitos mínimos para competir no mercado. Por esse ponto de vista, além da qualidade cultural, estética e artística da peça produzida, é preciso considerar sua dimensão comercial da atividade, ou seja, critérios de quantidade compatível com o mercado que se pretende atingir, qualidade constante e respeito a prazos de entrega e também de forma a remunerá-los mais vantajosamente.

A análise dos relatórios anuais, a observação dos grupos e a revisão bibliográfica revelam que os grupos observados não parecem ter acompanhado a evolução do ambiente de negócios, tanto pelos efeitos da atividade caracterizada de forma estigmatizada (baixa qualidade, associada a classes baixas da sociedade), quanto por sua própria desorganização produtiva. Há, no entanto, um fator ao qual deve ser atribuído um forte impacto na resistência à qualificação por parte do artesão: o Paternalismo, que conforme estudado por Freitas (in: Motta e Caldas 1997) entre outros (Moreira 2005, Sobral e Peci 2008) tem sua origem em dois traços que marcam profundamente a sociedade e cultura brasileiras: (1) a hierarquia institucionalizada numa sociedade histórica e rigidamente estratificada e acostumada a situação de um poder aristocrático, concentrado, imortalizado na figura do senhor de engenho, restando aos subordinados apenas uma aceitação passiva deste modus vivendi (postura de espectador); e (2) o personalismo que se vale das relações pessoais para romper esta rígida hierarquia estabelecida. 
Desta forma o paternalismo, ora motivado por boa vontade e proteção, ora por interesses menos altruístas por parte das autoridades, entidades e pessoas que procuravam apoiar os artesãos, manifesta-se em ações que consistem em fazer parte do trabalho pelos artesãos, ou seja, na maioria das vezes retirar as peças na casa do artesão, na quantidade que ele tinha se disposto a fazer, com qualidade inconstante, transportá-las e vendê-las em feiras, bazares etc., para logo depois do evento entregar, em dinheiro, o valor obtido ao artesão, sem que nenhum desses serviços Ihes fosse cobrado (Santos 2007).

\section{Paradigmas de comportamento e suas consequências}

Aparentemente, atitudes deste tipo geraram três paradigmas de comportamento nos grupos de artesãos observados, que corroboram "as características das organizações que respondem apenas indiretamente aos valores mercantis e funcionalistas" estudadas por Ramos (1989 apud Vergara e Silva 2007) com suas respectivas consequências:

(a) Envolvimento apenas com a produção que tem como resultado as seguintes situações: os artesãos são levados acreditar que produzir é mais difícil e importante do que vender; se dedicarem mais à produção relegando a gestão de seu negócio (planejamento, organização e controle) e comercialização a um segundo plano; não se preocuparem em entender como o mercado funciona, nem com o cliente e sua satisfação e menos ainda em como melhorar suas vendas; pouco evoluírem, por desconhecer a demanda e a razão efetiva pela qual o cliente comprou ou não seu produto (pela função ou design?); desconhecerem a sua concorrência e, portanto, não aprender com ela e nem saber como enfrentá-la.

(b) Plena liberdade para a produção conduzindo-os aos seguintes efeitos: produzirem o que gostam e como bem entendem, ou seja, para eles próprios e não para os clientes, por isso muitas vezes, sem respeitar as medidas-padrão do mercado, etc., o que afeta gravemente a aceitação do produto por parte do consumidor; não terem compromisso, disciplina e organização nem com o local de trabalho, nem com horários e prazos e nem tão pouco com a forma de fazer, o que compromete seriamente a produção em termos de quantidade, de padrão e constância de qualidade e de respeito a prazos de entrega; acreditarem que não precisem suportar nenhum tipo de pressão (por serem seus próprios patrões), por isso tornarem-se pouco disciplinados e refratários a críticas e pressões de toda espécie, como as que vêm do mercado: prazos de entrega, padrões a serem respeitados, etc.; terem a impressão de que trabalhar isoladamente é viável, reforçando o comportamento individualista e minando, desta forma, a importância e a força do trabalho cooperativo.

(c) Necessidade de apoio constante à produção artesanal, o que leva os artesãos a: não aprenderem a levar em consideração na composição do preço, os custos 
ligados à logística e venda como combustível, custo do espaço, salário do vendedor, embalagens, etc.; tornarem-se dependentes da boa vontade alheia e como consequência acomodados e com baixa autoestima, por se julgarem incapazes de fazerem tudo sem ajuda; acreditarem que precisam ser protegidos ou ter tratamento diferenciado dos demais componentes da sociedade; esperarem sempre obter resultados rápidos por precisarem do dinheiro (imediatismo) (Vergara e Silva 2007); não se encararem como profissionais.

Sob a ótica negocial, a junção desses três paradigmas de comportamento na maioria dos artesãos observados, culminou no distanciamento do mercado, tanto pelo lado de desejos e necessidades de uma demanda ideal, quanto, pelo lado da oferta. Ou seja, o estudo detectou uma visão dependente, não sustentável do artesão paulista, na compreensão da sua atividade como uma fonte de renda e emprego lucrativa, não dependente da boa vontade e dos recursos de políticas e entidades governamentais ou do terceiro setor, de cunho assistencialista. Resulta daí a desorganização generalizada da produção, gestão, logística, promoção e comercialização, e na resistência em se adotar o cooperativismo para enfrentar o mercado, na falta de profissionalismo dos artesãos e por fim numa postura de forte dependência e comodismo acompanhada por uma mentalidade fatalista e imediatista e que em grande parte coincide com os problemas já apontados por Marinho (2006).

É possível sugerir que a falta de uma visão negocial, sistêmica e estratégica pode conduzir a atividade cada vez mais ao reforço de sua estigmatização e a uma precariedade ainda maior de seus atores. Realidade a qual o setor artesanal não pode se furtar, ainda mais quando a alternativa do chamado comércio ético/solidário, que visa o aumento de renda de pequenos produtores marginalizados pelo comércio convencional por meio de acesso a mercados de sociedades desenvolvidas, ainda é bem menor que o comércio comum (França 2003) e por isso ainda incapaz de absorver toda a produção.

A soma do comportamento dos artesões e de erros nas intervenções se refletiu diretamente tanto na dificuldade de manutenção dos grupos, quanto no alcance dos atacadistas, desta forma apesar dos grupos terem fornecido para lojistas, a incapacidade de atender aos pedidos em termos de quantidade, qualidade e prazos de entrega dificultou em muito o estabelecimento de relações comerciais duradouras.

\section{Sugestões e direcionamentos para futuras pesquisas}

O advento de grandes eventos internacionais como a Copa do Mundo de Futebol, em 2014, e das Olimpíadas, em 2016, deve incrementar ainda mais o Turismo (MTUR 2011). A produção artesanal pode se beneficiar diretamente deste contexto, tanto em termos de geração de emprego quanto de renda. É preciso ter em mente, porém, que estes são eventos pontuais e não se pode ignorar que 
a maior parte do turismo no Brasil ainda é composta por turistas domésticos (MTUR 2011).

No Brasil $98 \%$ das empresas são micro e pequenas empresas gerando $67 \%$ das ocupações, mas apenas $20 \%$ do PIB (SEBRAE 2005), nas quais a mera aplicação de modelos consagrados de gestão podem não surtir efeito, havendo a necessidade de se repensar, adaptar ou criar novos modelos adequados a esta realidade. Um exemplo que merece reflexão vem de Bangladesh onde Muhammad Yunus, Prêmio Nobel da Paz em 2006, rompeu o paradigma de negócios bancários estabelecido, emprestando dinheiro a pequenos negócios sem garantias, gerando um círculo virtuoso de combate à pobreza e geração de novos negócios. Por meio de atividades deste tipo a economia do país se movimentou e o banco tornou-se um negócio bem sucedido com baixíssima taxa de inadimplência, exemplo que é hoje copiado por vários países do mundo (Exame.com 2006). Este exemplo estimula a reflexão sobre a necessidade de considerar modelos inovadores e não ortodoxos de gestão aplicados à atividade artesanal, que repitam este tipo de círculo virtuoso.

Dessa forma ao considerar o setor artesanal como atividade merecedora de uma abordagem gerencial objetiva, sistêmica e estratégica é preciso abstrair dimensões paternalistas e baseadas em uma visão assistencialista. Um bom motivo para este tipo de proposição é que o artesanato não pode nem deve ser encarado essencialmente como arte, mas sim como um tipo peculiar de indústria, mais dependente da intervenção manual do seu produtor, mas que tem como fundamento a oferta seriada de objetos com valor decorativo, estético e utilitário, muitas vezes com abordagem artística mas que é, sendo, portanto, um negócio que gera emprego e renda.

Neste sentido, mais pesquisas quantitativas com base em dados secundários do MDIC, MDA, SEBRAE (todos de abrangência nacional) seriam bastante úteis para melhor delinear a real dimensão deste setor, que apesar de ter recebido uma atenção aumentada por parte do Ministério do Desenvolvimento, Indústria e Comércio nos últimos anos, ainda merece maior atenção acadêmica e de gestão de políticas públicas, pelo seu grande potencial inclusivo e sustentável no combate à pobreza.

A construção de indicadores variados para o setor pode ser valiosa para nortear novas intervenções e uma nova gestão mais integradora, cabendo, assim, estudos que avaliassem a extensão dos resultados (em suas múltiplas dimensões) das ações empreendidas no sentido da profissionalização dos grupos de artesãos como, por exemplo:

- Quais ações implicam em reais aumentos de renda?;

- Há correlações entre atividades de qualificação e o aumento de absorção de novos artesãos? 
- A formação de grupos cooperativados, mais organizados, aumentam a representatividade social de seus componentes?

-Qual a contribuição as entidades podem oferecer pelo promoção das atividades e produtos artesanais, de forma coordenada, com uso das disciplinas da comunicação integrada de marketing?;

- O quanto estas atividades podem gerar em termos de valor pelo aumento de reconhecimento público?

-Quais os fatores podem contribuir para aumentar a autonomia e a maturidade gerencial do grupo, assumindo forma de associações, cooperativas ou micro empresas?

Da mesma forma, é recomendável pesquisar os pontos críticos que mereceriam maior atenção nas intervenções, investigando os motivos do fracasso da continuidade dos grupos. Teriam sido deficiências externas, como pouca vendagem? Falta de apoio da prefeitura (por exemplo: espaço público para comercialização, transporte de peças para eventos ou grandes encomendas)? Há possibilidade de que o aumento da qualificação gerencial leve à descaracterização de sua tipicidade (quando pré-existente) ou restrição da capacidade criativa do grupo (em função das intervenções)? Teriam sido deficiências em termos de relações humanas, derivadas de aspectos não produtivos, como desentendimento entre membros do grupo?

O que leva a refletir se a contraposição entre produção artesanal (domínio integral da produção) versus produção lindustrial (domínio parcial da produção) ainda é válida, uma vez que não se pode comparar a simplicidade do ambiente de negócios pregresso à Revolução Industrial com a complexidade do mercado globalizado. Assim a questão que se levanta é se os artesãos, que geralmente já tem déficits anteriores de aprendizado (Soares 2011), têm condições efetivas de se profissionalizarem a ponto de gerirem sozinhos as diferentes funções gerenciais (de produção, finanças, logística, promoção e comercialização), cabendo aí uma discussão mais aprofundada sobre a proposição de qualificação de artesãos mais vocacionados para atividades de gestão, que poderiam se especializar otimizando assim seus esforços, ou então a inevitabilidade do paternalismo, como condição de sustentabilidade econômica e negocial da atividade (Vergara e Silva 2007).

Por fim, é preciso considerar a possibilidade de adaptação do conceito de incubadoras tecnológicas (apesar de comumente associadas a eletrônicos, softwares, etc., o termo "tecnologia" se refere a um conjunto de conhecimentos sobre um ofício, arte ou técnica (Ferreira 2004)), o que permitiria aos grupos de artesãos amadurecerem sua organização cooperativa e sua capacidade gerencial. Neste sentido uma linha de pesquisa que se aprofunde nos modelos latino-americanos (ONU 2010), onde há forte presença do Estado nesta atividade, pode servir de benchmarking para a atividade artesanal brasileira e paulista. 


\section{Limitações}

No que diz respeito às limitações deste artigo, ao enveredar por ramos pouco estudados, a primeira dificuldade que se coloca é a falta de outros estudos empíricos e mesmo de um quadro conceitual amadurecido e compartilhado.

Também não se pode negligenciar o caráter multidisciplinar que a análise deste ramo da Economia Criativa incita, resultando na amplitude de variáveis a serem pesquisadas, e mesmo que limitadas ao enfoque estudado, podem parecer leves na abordagem e conteúdo das seções. A abordagem não-estruturada também dificulta delimitar os fatores a serem observados, bem como a imparcialidade na análise.

Cabe ainda considerar que parte da agenda de pesquisas propostas pode ser de grande envergadura, necessitando da cooperação de esforços entre pesquisadores coordenados geograficamente, e com o aporte de várias áreas de conhecimento.

Apesar destas consideráveis limitações, o esforço de refletir estrategicamente o passado e presente do Setor Artesanal, considerando não apenas sua dimensão negocial, mas também sociocultural, é uma contribuição ao estímulo e conjugação de esforços multidisciplinares na desconstrução de seu estigma e na convergência de reflexões acadêmicas e práticas gerenciais. Esforços desse tipo, que envolvam maior aprofundamento teórico, mas que também ofereçam condições de aplicação gerencial, certamente contribuirão para alavancar este setor de grande potencial, inclusivo e sustentável, para ocupar o espaço que lhe cabe no desenvolvimento econômico do país.

\section{Referências}

Bauman Z. Globalização: as conseqüências humanas. Rio de Janeiro: Jorge Zahar, 1999.

Caldas MP. Santo de casa não faz milagre. In: Motta FP, Caldas MP. Cultura organizacional e cultura brasileira. São Paulo: Atlas, 1997.

Cipiniuk A. Design e artesanato: aproximaçôes, métodos e justificativas. In: 70 Congresso de Pesquisa e Desenvolvimento em Design, Paraná: UFPR, 2006. Disponível na internet em: http://www.design.ufpr.br/ped2006/errata/Design\%20e\%20artesanato_\%20ap roxima\%E7\%F5es,\%20m\%E9todos\%20e\%20justificativas.pdf [ Acesso em 16 abr. 2010].

Damante H. Folclore brasileiro: São Paulo/Rio de Janeiro: MEC/FUNARTE/SAC, 1980. 
D'Ávila JS. O artesão tradicional e seu papel na sociedade contemporânea. In: Ribeiro B. (Org.). O artesão tradicional e seu papel na sociedade contemporânea. Rio de Janeiro: FUNARTE, 1984.

Exame.Com. Muhammad Yunus, criador do microcrédito, ganha o Nobel da Paz. Exame.com 13 de outubro de 2006. Disponível na internet em: http://exame.abril.com.br/economia/mundo/noticias/muhammad-yunuscriador-do-microcredito-ganha-o-nobel-da-paz-m0114107 [Acesso em 29 mai. 2010].

Ferreira ABH. Novo dicionário da língua portuguesa. Curitiba: Positivo, 2004.

França CL. (Org.). Comércio ético e solidário no Brasil. São Paulo: Fundação Friedrich Ebert/ILDES, 2003.

Freitas A. Traços brasileiros para uma análise organizacional. In: Motta F, Caldas MP. Cultura organizacional e cultura brasileira. São Paulo: Atlas, 1997.

Gilmore JH, Pine IB. Autenticidade: tudo o que os consumidores realmente querem. Rio de Janeiro: Elsevier, 2008.

Autor MA, Silva APO. Um estudo exploratório do novo luxo: fatores e segmentos de valores e motivações dos consumidores. In: XXXIII EnANPAD 2009 Encontro Nacional da ANPAD, 2009, São Paulo.

Holanda SB. Caminhos e fronteiras. São Paulo: Companhia das Letras, 1994.

Lewis D, Bridges D. A alma do novo consumidor. São Paulo: Makron Books, 2004.

Lima RG. Artesanato e arte popular: duas faces de uma mesma moeda? Centro Nacional de Folclore e Cultura Popular (CNFCP); Instituto de Patrimônio Histórico e Artístico Nacional (IPHAN), 2003. Disponível na internet em: http://www.cnfcp.gov.br/pdf/Artesanato/Artesanato_e_Arte_Pop/CNFCP_Artesa nato_Arte_Popular_Gomes_Lima.pdf [ Acesso em 29 mai. 2010].

Marinho HS. Por uma teorização das organizações de produção artesanal: habilidades produtivas nos caminhos singulares do Rio de Janeiro. Tese (Doutorado) - Escola Brasileira de Administração Pública e de Empresas (FGVRJ), 2006.

Martins GA, Theóphilo CR. Metodologia da investigação científica para ciências sociais aplicadas. 2a.ed. São Paulo: Atlas, 2009.

Ministério do Desenvolvimento da Indústria e Comércio (MDIC). Site institucional. Brasília, 2011. Disponível na internet em: http://www.mdic.gov.br/sitio/ [Acesso em 16 abr. 2011].

Ministério do Desenvolvimento da Indústria e Comércio (MDIC). Portaria 29, de 05 de outubro de 2010, DOU seção 1, páginas 100 a 102. Disponível na internet 
em

http://www.In:.gov.br/visualiza/index.jsp?data=06/10/2010\&jornal=1\&pagina $=100 \&$ totalArquivos=152 [ Acesso em 29 mai. 2010].

Ministério do Desenvolvimento da Indústria e Comércio (MDIC). Site institucional Aprendendo a Exportar Artesanato, Brasília, 2011. Disponível na internet em: http://www.aprendendoaexportar.gov.br/artesanato/000_sobre_frameset.htm [ Acesso em 16 abr. 2011].

Megale NB. Folclore brasileiro. 4a.ed. Rio de Janeiro: Vozes, 2003.

Ministério da Cultura (MINC). Cultura em números. Brasília: Ministério da Cultura, 2010a.

Ministério da Cultura (MINC). Programa Cultural para o Desenvolvimento do Brasil. Brasília: Ministério da Cultura, 2010b.

Ministério da Cultura (MINC)/Instituto Brasileiro de Geografia e Estatística (IBGE). Sistema de Informações e Indicadores Culturais 2003-2005. Rio de Janeiro: IBGE, 2006.

Moreira CAA. O paternalismo nas organizações brasileiras: reflexões à luz da análise cultural de empresas do pólo têxtil de Americana. (Tese) Escola de Administração de Empresas (FGV-SP), 2005.

Ministério do Turismo (MTUR). Site institucional. Brasília, 2011. Disponível na internet em: http://www.turismo.gov.br/turismo/ [Acesso em 23 abr. 2011].

Organização Mundial de Turismo (OMT). Compendio de estadísticas del turismo. Madri: OMT, 2003.

Organização das Nações Unidas (ONU). Creative economy report: a feasib/e development option, 2010. Disponível na internet em: http://www.unctad.org/en/docs/ditctab20103_en.pdf [Acesso em: 04 jun. 2011].

Pereira JBB. O artesanato na cultura. In: Biblioteca Eucatex de Cultura Brasileira. Arte no Trabalho. São Paulo: Grupo Eucatex, 1991.

Prado Júnior C. Formação do Brasil contemporâneo. 23a.ed. São Paulo: Brasiliense, 2001.

Quintana HG. O trailer no sistema de marketing de cinema: à procura do quinto elemento. Anais do XXVI Congresso Anual em Ciência da Comunicação, Intercom, 2003.

Reis ACF. (Org.). Economia criativa como estratégia de desenvolvimento: uma visão dos países em desenvolvimento. São Paulo: Itaú Cultural, 2008. 
Ribeiro D. O povo brasileiro: a formação e o sentido do Brasil. São Paulo: Cia. das Letras, 1995.

Santos R. Artesanato paulista: técnicas e materiais da terra. In: Setubal MA. (Coord.). Terra paulista: histórias, arte, costumes. vol.3. São Paulo: CENPEC, Imprensa Oficial do Estado de SP, 2004.

Santos TS. O artesanato como elemento impulsionador no desenvolvimento local em municípios brasileiros. In: XIX Congresso de Pós-Graduação da UFLA, Minas Gerais: UFLA, 2010. Disponível na internet em: http://www.sbpcnet.org.br/livro/lavras/resumos/1217.pdf [ Acesso em 29 mai. 2010].

SEBRAE. Termo de referência. Brasília: Programa SEBRAE de Artesanato, 2004.

SEBRAE, A presença das micro e pequenas empresas na economia brasileira. Brasília: SEBRAE, 2005. Disponível na internet em: http://www.saopaulo.sp.gov.br/spnoticias/lenoticia.php?id=101057\&c=6 [ Acesso em 29 mai. 2010].

SEBRAE-SP. Relatório anual Programa de Artesanato. São Paulo: SEBRAE-SP, 2001; 2002; 2003; 2004; 2005.

Silva AL, Vidal LB. O sistema de objetos nas sociedades indígenas: arte e cultura material. In: A Temática Indígena na Escola, MEC/MARI/UNESCO, 1995.

Sobral F, Peci A. Administração, Teoria e prática no contexto brasileiro. São Paulo: Pearson, 2008.

Souza M. Brasil das artes, São Paulo: Imagem Data, 1998.

Superintendência do Trabalho Artesanal nas Comunidades (SUTACO). Site institucional, São Paulo, 2011. Disponível na internet em: http://www.sutaco.com.br/ [ Acesso em 29 mai. 2011].

Vergara S. Silva H. Organizações artesanais: um sistema esquecido na teoria das organizações. Rev Port Bras Gestão, 2007, 6(3):32-38. 